Https://online.unisc.br/seer/index.php/cadpesquisa

ISSN on-line: $1677-5600$

Doi: $10.17058 / c p . v 31 i 1.12864$

Universidade de Santa cruz do Sul - Unisc

Recebido em 03 de Dezembro de 2018 Aceito em 20 de Março de 2019 Autor para contato: carmine.hister@ufsm.br

\title{
Determinação de compostos fenólicos e avaliação do potencial genotóxico e antiproliferativo de extratos aquosos das folhas de Psidium cattleianum Sabine (Myrtaceae)
}

Determination of phenolic compounds and assessment of the genotoxic and antiproliferative potential of Psidium cattleianum Sabine leaf aqueous extracts

\author{
Carmine Aparecida Lenz Hister \\ Universidade Federal de Santa Maria - UFSM - Santa Maria - Rio Grande do Sul - Brasil \\ Kassia Cauana Trapp \\ Universidade Federal do Rio Grande do Sul - UFRGS - Porto Alegre - Rio Grande do Sul - Brasil \\ Aline Augusti Boligon \\ Solange Bosio Tedesco \\ Universidade Federal de Santa Maria - UFSM - Santa Maria - Rio Grande do Sul - Brasil
}

\section{Resumo}

Psidium cattleianum é uma espécie nativa do Brasil, conhecida como araçá, e valorizada pelo seu uso na medicina popular. $O$ trabalho visou avaliar a atividade genotóxica e antiproliferativa do extrato aquoso de $P$. cattleianum usando o teste de Allium cepa, bem como testar sua capacidade de reverter mutações ocasionadas pela exposição ao glifosato e ainda determinar os compostos fenólicos presentes nesse extrato. Folhas foram coletadas em quatro acessos: Cerro Largo, Segredo, Tupanciretã e Silveira Martins. Os extratos foram preparados por decocção das folhas em duas concentrações: 15 g.L- ${ }^{1}$ e 75 g.L- ${ }^{1}$. Água destilada foi utilizada como controle negativo e glifosato $2 \%$ como controle positivo. Foram analisadas 8000 células de raízes de cebola por tratamento. Amostras dos extratos aquosos foram analisadas por cromatografia líquida de alta eficiência - CLAE. A análise estatística foi realizada pelos testes Qui-quadrado e Scott-Knott $(p<0,05)$. Os resultados mostraram que os extratos inibiram a divisão celular de raízes de cebola. Apenas o acesso de Cerro Largo na concentração 15 g.L-1 apresentou genotoxicidade. Os extratos testados na recuperação reverteram parcialmente as alterações cromossômicas. A CLAE mostrou a predominância de quercitrina, quercetina e isoquercitrina nos extratos analisados. Conclui-se que os extratos aquosos de araçá são citotóxicos, pois possuem atividade antiproliferativa sobre a divisão celular de $A$. cepa.

\section{Abstract}

Psidium cattleianum is a Brazilian native species valued for its use in popular medicine. This study aims at evaluating the genotoxic and antiproliferative activity of $P$. cattleianum aqueous extracts using Allium cepa test, as well as test their ability to revert mutations resulting from glyphosate exposure and also determine the phenolic compounds present in this extract. Leaves of four accessions were collected: Cerro Largo, Segredo, Tupanciretã and Silveira Martins. Extracts were prepared by decoction of leaves in two concentrations: 15 g.L- ${ }^{1}$ and 75 g.L-1 ${ }^{1}$. Distilled water was used as negative control, whereas a $2 \%$ glyphosate solution served as positive control. 8000 cells were analyzed in each treatment. The extract samples were analyzed by high-performance liquid chromatography - HPLC. Statistical analysis was conducted using Chi-square and Scott-Knott tests ( $p$ $<0,05)$. The results showed that the extracts inhibited the cell division of the onion roots. Genotoxicity was observed only in the accession collected in Cerro Largo at a concentration of 15 g.L1. As for reversion, the extracts partially reverted chromosomal alterations. The HPLC showed a predominant presence of quercitrin, quercetin and isoquercitrin in the extracts analyzed. We concluded that the aqueous extracts of strawberry guava were cytotoxic, because they cause antiproliferative activity on the cell division of $A$. серa.

\section{Palavras-chave}

Allium cepa. Araçá. Cromatografia líquida. Genotoxicidade. Índice mitótico.

\section{Keywords}

Allium cepa. Strawberry guava. Liquid chromatography.

Genotoxicity. Mitotic index. 


\section{Introdução}

Há milhares de anos o homem utiliza os recursos vegetais com fins terapêuticos. Em todo o mundo, aproximadamente $85 \%$ das pessoas são praticantes de sistemas tradicionais de cura a base de plantas (Rai et al., 2000). No entanto, o consumo indiscriminado de chás ou derivados merece uma atenção especial, devido principalmente ao desconhecimento de seus constituintes químicos, que podem causar, muitas vezes, mais danos à saúde que benefícios. Os prováveis efeitos tóxicos de muitas plantas ainda são ignorados, portanto devem-se utilizar apenas aquelas cujos efeitos sejam bem conhecidos (Martins et al., 2003).

Uma das espécies bastante utilizada na medicina popular é Psidium cattleianum Sabine, conhecida popularmente como araçá. Além do consumo de seus frutos in natura, é uma espécie utilizada com fins medicinais, sendo que experimentos com extratos de suas folhas demonstraram atividade antiproliferativa em células de câncer - gástrico, da mama, do cólon, do fígado e do pulmão (Moon et al., 2011; Medina et al., 2011; Jun et al., 2011; Im et al., 2012). Extratos de seus frutos e folhas também apresentaram atividade antimicrobiana (Medina et al., 2011; Jun et al., 2011; Menezes et al., 2010; Brighenti et al., 2008).

A detecção de agentes mutagênicos presentes em extratos de plantas medicinais pode ser realizada citologicamente em organismos-teste pela inibição celular; interrupção na metáfase; indução de aberrações cromossômicas, numérica e estrutural, que vão desde a fragmentação cromossômica à desorganização do fuso mitótico (Tedesco e Laughinghouse IV, 2012). A utilização de organismos vegetais em biotestes para detecção de efeitos adversos de produtos químicos, extratos de plantas e misturas complexas sobre os cromossomos destes organismos-alvo é bastante difundida, entre as espécies mais utilizadas estão: Lactuca sativa L. (alface), Vicia alba L., Lycopersicum esculentum Mill. (tomate) e Allium cepa (cebola).

O método amplamente utilizado de avaliação de alterações cromossômicas em raízes de A. cepa é validado como um eficiente teste para análise e monitoramento in situ da genotoxicidade de substâncias ambientais pelo Programa Internacional de Segurança Química (PISQ, OMS) e pelo Programa Ambiental das Nações Unidas (United Nations Environment Programme - UNEP) (Cabrera e Rodriguez, 1999; Bagantini et al., 2007; Fachinetto et al., 2007; Frescura et al., 2013a). Em experimento de mutagenicidade de infusões de Psidium guajava L. e Achillea millefolium L., realizado por Teixeira et al. (2003), utilizando células meristemáticas de raízes de cebola, células de medula óssea de ratos e linfócitos humanos como bioindicadores, os autores observaram os mesmos resultados para os três tipos de células eucarióticas testadas, reforçando a confiabilidade do teste de $A$. cepa em estudos citogenéticos.

Além disso, a utilização de perfis cromatográficos ou fingerprints, como aqueles obtidos por Cromatografia Líquida de Alta Eficiência (CLAE), são importantes para a análise de extratos vegetais uma vez que possibilita obter a representatividade dos múltiplos compostos químicos presentes na amostra em uma única análise (Alaerts et al., 2007).

Dada a importância ecológica, econômica e social, e ainda a utilização de $P$. cattleianum na forma de chá (extrato aquoso) na medicina popular como antidiarreico, antidisentérico e para tratar de doenças das vias urinárias, buscou-se testar a toxicidade do extrato aquoso de suas folhas por meio da existência ou não de atividade genotóxica, antigenotóxica e antiproliferativa sobre a divisão meristemática em células de pontas de raízes de $A$. cepa, assim como determinar os compostos fenólicos presentes no extrato. 


\section{Material e métodos}

\section{Coleta de material botânico e preparo dos extratos aquosos}

Folhas de araçá [Psidium cattleianum Sabine (Myrtaceae)] de quatro acessos de municípios do Rio Grande do Sul (Cerro Largo $=\mathrm{CL}$, Segredo $=\mathrm{SE}$, Silveira Martins $=$ SiM e Tupanciretã $=$ TU) foram coletadas antes do período de florescimento.

As folhas foram secas à temperatura ambiente e armazenadas em sacos de papel até o uso. Os extratos das folhas foram preparados por decocção das folhas por cinco minutos, na concentração usual de 15 gramas de folhas secas em 1 litro de água destilada (Anvisa, 2010) e também 75 g. L $^{-1}$ (cinco vezes mais concentrado).

\section{Tratamentos e critérios de análise}

Treze grupos de quatro bulbos de cebola, cada grupo correspondendo a um tratamento, foram colocados em água destilada para enraizamento, por aproximadamente 72 horas. Após o enraizamento, um grupo permaneceu em água destilada, sendo o controle negativo (CN), e outro grupo foi colocado em solução de glifosato a $2 \%$, sendo o controle positivo (CP), pois este comprovadamente induz alterações cromossômicas e inibe a divisão celular em células meristemáticas de A. cepa (Souza et al., 2010). Oito grupos de bulbos foram transferidos para os extratos aquosos preparados por decocção em diferentes concentrações. Todos os bulbos permanecerem em tratamento por 24 horas em temperatura ambiente. Outros três grupos também foram colocados em solução de glifosato a $2 \%$ para outro teste afim de avaliar a antigenotoxicidade dos extratos, o qual envolveu um pós-tratamento ou seja, após 24 horas em glifosato os bulbos foram transferidos para água destilada e para dois extratos aquosos de acessos diferentes, por mais 24 horas, para avaliar se haveria uma recuperação do efeito mutagênico do glifosato.

Em suma, os treze grupos de bulbos de cebola foram distribuídos nos seguintes tratamentos:

- $\quad \mathrm{T} 1-$ água destilada (controle negativo $=\mathrm{CN}$ );

- $\quad$ T2 - extrato aquoso do acesso de Cerro Largo na concentração de 15 g.L-1 (CL 15);

- T3 - extrato aquoso do acesso de Cerro Largo na concentração de 75 g.L-1 (CL 75);

- T4 - extrato aquoso do acesso de Segredo na concentração de 15 g.L-1 ${ }^{1}$ (SE 15);

- $\quad$ T5 - extrato aquoso do acesso de Segredo na concentração de 75 g.L-1 (SE 75);

- $\quad$ T6 - extrato aquoso do acesso de Tupanciretã na concentração de 15 g.L-1 (TU 15);

- $\quad$ T7 - extrato aquoso do acesso de Tupanciretã na concentração de 75 g.L-1 (TU 75);

- T8 - extrato aquoso do acesso de Silveira Martins na concentração de 15 g.L-1 (SiM 15);

- T9 - extrato aquoso do acesso de Silveira Martins na concentração de 75 g.L-1 (SiM 75);

- $\quad \mathrm{T} 10-$ glifosato $2 \%$ (controle positivo $=\mathrm{CP}$ );

- T11 - pós-tratamento em água destilada;

- T12 - pós-tratamento em extrato aquoso TU 15;

- T13 - pós-tratamento em extrato aquoso SiM 15. 
Após o período de aplicação dos tratamentos, as radículas dos bulbos de cebola foram coletadas, fixadas em etanol: ácido acético na concentração 3:1 por 24 horas, e em seguida foram armazenadas em etanol $70 \%$ sob refrigeração para posterior análise. Para a confecção das lâminas, a técnica de esmagamento desenvolvida por Guerra e Souza (2002) foi utilizada, utilizando a orceína acética $2 \%$ como corante do material genético.

A análise das lâminas ao microscópio óptico foi realizada no aumento de 40X, sendo que para cada bulbo foram feitas duas repetições, preparando-se duas lâminas. Mil células por lâmina foram analisadas, totalizando 2000 células por bulbo, e 8000 células por tratamento. Os valores dos índices mitóticos (IM) foram calculados com base na razão entre o número de células em divisão e o número total de células analisadas. Além das fases da divisão celular, avaliou-se a presença de irregularidades, como: quebras cromossômicas, pontes, cromossomos perdidos ou atrasados e presença de micronúcleos, calculando-se o índice genotóxico, com base na razão entre a quantidade de células com alterações cromossômicas e o número total de células analisadas.

\section{Análise dos extratos por cromatografia líquida de alta eficiência (CLAE-DAD)}

Uma amostra de cada extrato, na concentração de 75 g. $\mathrm{L}^{-1}$, foi separada para a realização de cromatografia líquida de alta eficiência com detector de arranjo de diodos (CLAEDAD), no Laboratório de Fitoquímica do Departamento de Farmácia Industrial da UFSM do Programa de Pós-Graduação em Ciências Farmacêuticas.

\section{Produtos químicos, aparelhos e procedimentos gerais}

Todos os reagentes químicos foram de grau analítico. Metanol, ácido acético, ácido gálico, ácido clorogênico, ácido elágico e ácido cafeico foram adquiridos da Merck (Darmstadt, Alemanha). Rutina, epicatequina, catequina, isoquercetina, quercetina, quercitrina e canferol foram adquiridos da Sigma Chemical Co. (St. Louis, MO, EUA). A cromatografia líquida de alta eficiência foi realizada com um sistema de CLAE (Shimadzu, Kyoto, Japão) e auto injetor Shimadzu (SIL-20A), equipado com bombas alternativas (Shimadzu LC-20AT) ligadas a um desgaseificador (20A5 DGU) com um integrador (CBM 20A), detector de arranjo de diodos (SPD-M20A) e software (LC solution SP1 1.22).

\section{Quantificação de compostos por CLAE}

As análises cromatográficas foram realizadas em fase reversa sob condições de gradiente utilizando coluna C18 $(4,6 \mathrm{~mm} \times 150 \mathrm{~mm})$ carregada com partículas de diâmetro 5 $\mathrm{mm}$, a fase móvel utilizada foi água contendo $2 \%$ de ácido acético (A) e metanol (B), e o gradiente de composição foi: 5\% (B) durante $2 \mathrm{~min}, 25 \%$ (B) até $10 \mathrm{~min}, 40,50,60,70$ e $80 \%$ (B) a cada $10 \mathrm{~min}$, seguindo o método descrito por Peroza et al. (2013) com pequenas modificações.

O fluxo usado foi de $0,6 \mathrm{~mL} / \mathrm{min}$, o volume de injeção de $40 \mathrm{~mL}$ e o comprimento de onda foi de $254 \mathrm{~nm}$ para o ácido gálico, $280 \mathrm{~nm}$ para catequina e epicatequina, $325 \mathrm{~nm}$ para o ácido cafeico, ácido elágico e ácido clorogênico, e $365 \mathrm{~nm}$ para rutina, quercetina, quercitrina, isoquercitrina e canferol. As amostras e a fase móvel foram filtradas através de filtro de membrana de 0,45 $\mathrm{mm}$ (Millipore) e em seguida desgaseificada por banho de ultrassom antes da utilização.

As soluções de referência foram preparadas na fase móvel para CLAE nas concentrações de $0,050-250 \mathrm{mg} \cdot \mathrm{mL}^{-1}$ para rutina quercetina, quercitrina, isoquercitrina, canferol, catequina e 
epicatequina; e 0,030-450 mg. $\mathrm{mL}^{-1}$ para ácido gálico, ácido clorogênico, ácido elágico e ácido cafeico. Os picos cromatográficos foram confirmados por comparação do seu tempo de retenção com os dos padrões de referência e por espectros de DAD (200 a $500 \mathrm{~nm}$ ). A curva de calibração para o ácido gálico foi: $Y=12739 x+1186,9(r=0,9994)$; ácido clorogênico: $Y=$ $11976 x+1206,5(r=0,9997)$, ácido cafeico: $Y=12573 x+1270,3(r=0,9996)$, ácido elágico: $Y=$ 13062x + 1269,3 $(r=0,9990)$, catequina: $Y=11968 x+1347,1(r=0,9995)$, epicatequina: $Y=$ 12763x + 1269,5 $(r=0,9993)$, quercetina: $Y=13184 x+1256,1(r=0,9999)$, isoquercetina: $Y=$ $11985 x+1359,7(r=0,9996)$, quercitrina: $Y=13065 x+1249,6(r=0,9993)$, rutina: $Y=13583 x+$ $1267,5(r=0,9998)$ e canferol: $Y=13423 x+1153,2(r=0,9998)$.

Todas as operações cromatográficas foram realizadas à temperatura ambiente e em triplicata. O limite de deteç̧ão (LOD) e o limite de quantificação (LOQ) foram calculados com base no desvio padrão das respostas, e a inclinação, usando três curvas analíticas independentes. LOD e LOQ foram calculados como 3.3 e $10 \mathrm{\sigma} / \mathrm{S}$, respectivamente, onde $\sigma$ é o desvio padrão da resposta, e S é a inclinação da curva de calibração (Boligon et al., 2013).

\section{Análise estatística}

O delineamento do experimento foi inteiramente casualizado. Os valores dos índices mitóticos foram comparados pelo teste Qui-quadrado $\left(\chi^{2}\right)$ a $5 \%$ de probabilidade de erro, com o auxílio do programa BIOESTAT 5.0 (Ayres et al., 2007). As médias dos compostos fenólicos resultantes da Cromatografia Líquida de Alta Eficiência (CLAE) foram comparadas utilizando-se o Teste de Scott-Knott $(p<0,05)$, com o auxílio de programa Assistat ${ }^{\circledR}$ (Silva, 2014), versão beta 7.7.

\section{Resultados e discussões}

Os resultados obtidos através da análise das células meristemáticas de raízes de $A$. cepa submetidas aos controles e aos tratamentos com extrato aquoso de $P$. cattleianum são mostrados na Tab. 1. Foi realizado o teste de Qui-quadrado para comparar o número de células irregulares (avaliação da genotoxicididade) e também os valores dos índices mitóticos (avaliação da citotoxicidade ou atividade antiproliferativa), de todos os tratamentos entre si.

\begin{tabular}{lccccc}
\hline Tratamentos & $\begin{array}{c}\text { Células em } \\
\text { interfase }\end{array}$ & $\begin{array}{c}\text { Células em } \\
\text { divisão }\end{array}$ & $\begin{array}{c}\text { Células com } \\
\text { irregularidades }\end{array}$ & $\begin{array}{c}\text { Índice } \\
\text { genotóxico - IG } \\
\text { (\%) }\end{array}$ & $\begin{array}{c}\text { Índice } \\
\text { mitótico - IM } \\
\text { (\%) }\end{array}$ \\
\hline CN & 7470 & 530 & 3 & $0,03 \mathrm{c}^{*}$ & $6,62 \mathrm{a}^{*}$ \\
\hline CL 15 & 7724 & 276 & 17 & $0,21 \mathrm{~b}$ & $3,45 \mathrm{~b}$ \\
\hline CL 75 & 7937 & 63 & 2 & $0,02 \mathrm{c}$ & $0,79 \mathrm{e}$ \\
\hline SE 15 & 7774 & 226 & 5 & $0,06 \mathrm{c}$ & $2,82 \mathrm{c}$ \\
\hline SE 75 & 7929 & 71 & - & $0,00 \mathrm{~d}$ & $0,89 \mathrm{e}$ \\
\hline TU 15 & 7729 & 271 & 6 & $0,07 \mathrm{c}$ & $3,39 \mathrm{~b}$ \\
\hline TU 75 & 7935 & 65 & - & $0,00 \mathrm{~d}$ & $0,81 \mathrm{e}$ \\
\hline
\end{tabular}




\begin{tabular}{llllll}
\hline SiM 15 & 7856 & 144 & 1 & $0,01 \mathrm{c}$ & $1,80 \mathrm{~d}$ \\
\hline SiM 75 & 7860 & 140 & - & $0,00 \mathrm{~d}$ & $1,75 \mathrm{~d}$ \\
\hline CP & 7743 & 257 & 59 & $0,73 \mathrm{a}$ & $3,21 \mathrm{~b}$ \\
\hline
\end{tabular}

$\mathrm{CN}=$ controle negativo (água destilada); $\mathrm{CL} 15$ = extrato aquoso do acesso de Cerro Largo na concentração de 15 g.L1; CL 75 = extrato aquoso do acesso de Cerro Largo na concentração de 75 g. $\mathrm{L}^{-1}$; SE 15 = extrato aquoso do acesso de Segredo na concentração de 15 g.L-1 ; SE 75 = extrato aquoso do acesso de Segredo na concentração de 75 g.L-1; TU 15 = extrato aquoso do acesso de Tupanciretã na concentração de 15 g.L-1 $;$ TU 75 = extrato aquoso do acesso de Tupanciretã na concentração de 75 g. L-1 ; SiM 15 = extrato aquoso do acesso de Silveira Martins na concentração de 15 g.L-1- SiM 75 = extrato aquoso do acesso de Silveira Martins na concentração de 75 g.L-1 ; CP = controle positivo (glifosato 2\%); *IG e IM seguidos pela mesma letra não diferem estatisticamente, comparados todos entre si pelo teste do Qui-Quadrado, a um nível de 5\% de probabilidade de erro.

Observa-se que apesar de todos os extratos na concentração de 15 g. $\mathrm{L}^{-1}$ diminuírem significativamente a proliferação celular, esta variou entre os acessos, indicando uma possível variabilidade genética entre os mesmos. Além disso, as diferenças nas condições edafoclimáticas dos locais onde os acessos foram coletados também têm papel importante no metabolismo vegetal e abundância de compostos fenólicos.

É possível verificar que a redução do índice mitótico (IM) foi ainda maior nos tratamentos com os extratos aquosos em concentração cinco vezes maior que a indicada (75 g. L $^{-1}$ ). Ou seja, em três dos acessos analisados (CL 75, SE 75 e TU 75) o valor do IM foi inversamente proporcional à concentração dos extratos de araçá. Resultados simulares foram relatados por Knoll et al. (2006) onde quanto mais concentradas as infusões de Pterocaulon polystachyum DC, maior a inibição da divisão celular e diminuição do índice mitótico de ponta de raízes de $A$. cepa.

Apenas nos tratamentos SiM 15 e SiM 75 não houve diferença significativa do IM entre as duas concentrações analisadas (IM $=1,8 \%$ e $1,75 \%$, respectivamente). Assim como resultados encontrados por Dias et al. (2014), os quais demonstraram que as infusões de Mikania cordifolia (L. F.) Willd. inibiram significativamente a divisão celular em ambas as concentrações ( 8 g. $\mathrm{L}^{-1}$ e $32 \mathrm{~g} . \mathrm{L}^{-1}$ ), indicando a ocorrência de atividade antiproliferativa das infusões, mais acentuadamente na menor concentração. Mesmo os tratamentos SiM 15 e SiM 75 apresentando intensa atividade antiproliferativa, estes não apresentaram genotoxicidade, pois não diferiram significativamente do $\mathrm{CN}$ (IG $=0,01 \%$ e $0 \%$, respectivamente).

Apesar de todos os tratamentos com extratos aquosos diminuírem a divisão celular, as alterações cromossômicas observadas nos tratamentos SE 15, TU 15 e SiM 15 foram irrelevantes (IG $=0,06 \%, 0,07 \%$ e $0,01 \%$, respectivamente) sendo estes considerados não genotóxicos (Fig. 1a e 1b). Comparativamente, Costa et al. (2008) observou que a mistura de compostos presentes nos extratos das folhas de $P$. cattleianum não apresentaram efeitos mutagênicos em alguns tipos de células in vivo de Mus musculus.

A exceção fica com o tratamento $\mathrm{CL} 15$, que apresentou o número de 17 alterações cromossômicas (IG = 0,21\%), como mostrado na Fig. 1c e 1d. Observações similares foram realizadas por Pastori et al. (2013) que demonstraram a presença de atividade genotóxica e antiproliferativa em infusões de folhas de guabiroba (Campomanesia xanthocarpa Berg.) usando o sistema-teste vegetal em cebola.

A atividade antimitótica sobre o meristema apical de raízes de cebola apresentada pelos extratos aquosos das cascas de Uncaria tomentosa (Willd.) DC provavelmente é parte do modo de ação destes no tratamento de câncer, que além da inibição eficaz da divisão celular - uma exigência para potenciais drogas anticâncer extraídas de plantas medicinais - necessita 
apresentar uma toxicidade mínima para células saudáveis do organismo tratado (Sheng et al., 2000; Kurás et al., 2006).

A Tab. 2 a seguir mostra o resultado da análise de antigenotoxicidade na qual foram realizados pós-tratamentos (ou tratamentos de recuperação) após a exposição das raízes ao glifosato.

\begin{tabular}{lccccc}
\hline Tratamentos & $\begin{array}{c}\text { Células em } \\
\text { interfase }\end{array}$ & $\begin{array}{c}\text { Células } \\
\text { em } \\
\text { divisão }\end{array}$ & $\begin{array}{c}\text { Células com } \\
\text { irregularidades }\end{array}$ & $\begin{array}{c}\text { Índice } \\
\text { genotóxico - IG } \\
\text { (\%) }\end{array}$ & $\begin{array}{c}\text { Índice } \\
\text { mitótico - } \\
\text { IM (\%) }\end{array}$ \\
\hline $\mathrm{CN}$ & 7470 & 530 & 3 & $0,03 \mathrm{e}^{*}$ & $6,62 \mathrm{a}^{*}$ \\
\hline $\mathrm{CP}$ & 7743 & 257 & 59 & $0,73 \mathrm{a}$ & $3,21 \mathrm{c}$ \\
\hline $\mathrm{CP}+$ água & 7724 & 276 & 26 & $0,32 \mathrm{~b}$ & $3,45 \mathrm{c}$ \\
\hline $\mathrm{CP}+$ TU 15 & 7807 & 193 & 9 & $0,11 \mathrm{~d}$ & $2,41 \mathrm{~d}$ \\
\hline $\mathrm{CP}+$ SiM 15 & 7676 & 324 & 17 & $0,21 \mathrm{c}$ & $4,05 \mathrm{~b}$
\end{tabular}

$\mathrm{CN}=$ controle negativo (água destilada); $\mathrm{CP}=$ controle positivo (glifosato $2 \%$ ); $\mathrm{CP}+$ água = glifosato $2 \%$ + póstratamento em água destilada; $\mathrm{CP}+\mathrm{TU} 15$ = glifosato $2 \%$ + pós-tratamento em extrato aquoso do acesso de Tupanciretã na concentração de 15 g.L $\mathrm{L}^{-1} ; \mathrm{CP}+\mathrm{SiM} 15$ = glifosato $2 \%$ + pós-tratamento em extrato aquoso do acesso de Silveira Martins na concentração de 15 g. L-1 $^{-}{ }^{*} I G$ e IM seguidos pela mesma letra não diferem estatisticamente, comparados todos entre si pelo teste do Qui-Quadrado, a um nível de 5\% de probabilidade de erro.

No que diz respeito aos tratamentos de recuperação (Fig. 1e e 1f), estes não mostraram diferença significativa entre os valores de IM do tratamento CP + água destilada e do CP, ou seja, a água não reverteu a ação antiproliferativa do glifosato. Porém, o número de irregularidades encontradas no $\mathrm{CP}+$ água reduziu pela metade. $\mathrm{O}$ efeito antiproliferativo do glifosato foi parcialmente revertido apenas após o tratamento CP + SiM 15, como também foi relatado em estudo utilizando extrato aquoso das espécies Psychotria brachypoda (Müll. Arg.) Briton e P. birotula Smith \& Downs como tratamento de recuperação após o glifosato (Frescura et al., 2013b). 


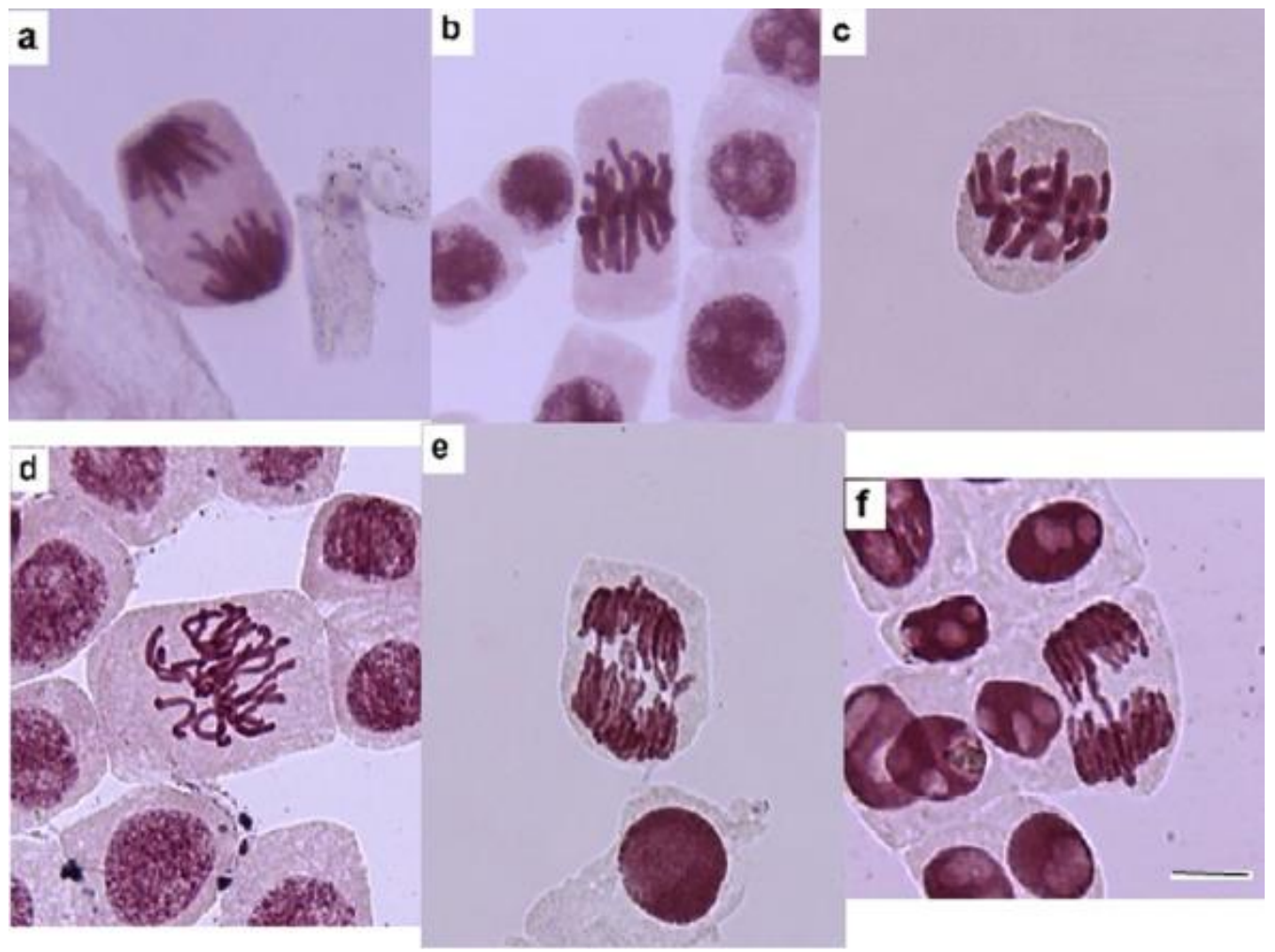

Além disso, em relação à antigenotoxicidade, todos os pós-tratamentos demonstraram uma redução significativa na ocorrência de irregularidades em relação ao controle positivo (CP). Os tratamentos de recuperação que utilizaram os extratos aquosos de araçá (CP + TU 15 e CP+ SiM 15) inclusive diminuíram significativamente as alterações cromossômicas em relação ao CP + água, sendo os acessos TU e SiM $\left(15\right.$ g. $\left.\mathrm{L}^{-1}\right)$ considerados antigenotóxicos. Da mesma forma que Sturbelle et al. (2010) revelaram que uma solução de Aloe vera $\mathrm{L}$. apresentava ação antimutagênica quando utilizada como pós-tratamento após o paracetamol, pelo teste de $A$. cepa.

A análise de CLAE revelou nos cromatogramas a presença de diferentes compostos fenólicos nos extratos aquosos das folhas de $P$. cattleianum: ácido gálico (pico 1 ), catequina (pico 2), ácido clorogênico (pico 3), ácido cafeico (pico 4), ácido elágico (pico 5), epicatequina (pico 6), rutina (pico 7), quercitrina (pico 8), isoquercitrina (pico 9), quercetina (pico 10) e canferol (pico 11), conforme pode ser observado no perfil cromatográfico da Fig. 2a, 2b, 2c e $2 d$. 
a

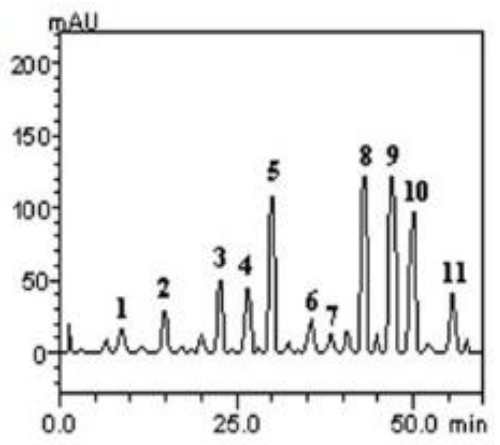

C

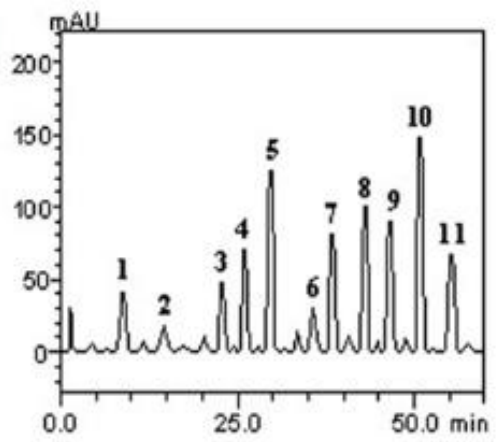

b

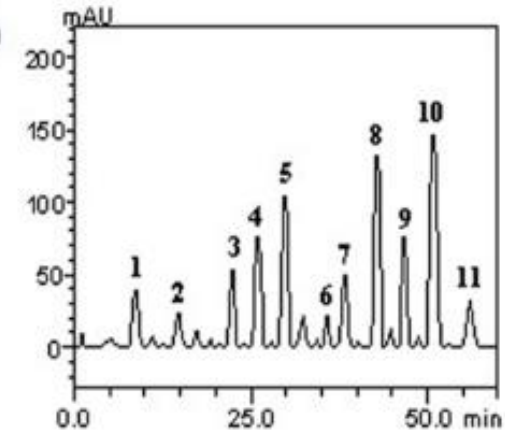

d

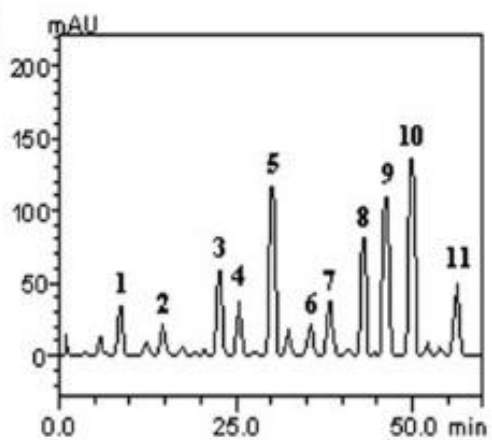

Os resultados da CLAE mostraram a predominância de quercetina (pico 10) nos acessos TU e SiM, e quercetina e quercitrina no acesso SE. O acesso $\mathrm{CL}$, diferentemente dos demais, possui a quercitrina (pico 8) e a isoquercitrina (pico 9) como compostos fenólicos majoritários. Compostos fenólicos, tais como flavonoides (quercitrina, isoquercitrina) tem como propriedade benéfica o sequestro de radicais livres (Decker, 1997). A presença do flavonoide quercitrina foi relatada em Solidago microglossa DC. (Torres et al., 1987; Roque et al., 1988; Pavanelo, 2014), o qual confere à espécie, de acordo com Smolarek et al. (2009), atividades anti-inflamatória e analgésica. Relembrando que foi o tratamento $\mathrm{CL} 15$ o único que demonstrou atividade genotóxica pelo teste de A. cepa.

A Tab. 3 mostra a quantidade média de cada um dos compostos fenólicos presentes nos extratos aquosos das folhas de $P$. cattleianum. 


\begin{tabular}{|c|c|c|c|c|c|c|}
\hline \multirow[t]{2}{*}{ Compostos } & $\begin{array}{l}\text { Extrato das } \\
\text { folhas } 75 \\
\text { g. } \mathrm{L}^{-1}(\mathrm{CL})\end{array}$ & $\begin{array}{l}\text { Extrato das } \\
\text { folhas } 75 \\
\text { g. } \mathrm{L}^{-1}(\mathrm{SE})\end{array}$ & $\begin{array}{l}\text { Extrato das } \\
\text { folhas } 75 \\
\text { g. } \mathrm{L}^{-1}(\mathrm{TU})\end{array}$ & $\begin{array}{l}\text { Extrato das } \\
\text { folhas } 75 \\
\text { g. } \mathrm{L}^{-1} \text { (SiM) }\end{array}$ & LOD & LOQ \\
\hline & \multicolumn{4}{|c|}{$\mathrm{mg} \cdot \mathrm{g}^{-1}$} & \multicolumn{2}{|c|}{$\mu \mathrm{g} \cdot \mathrm{mL}^{-1}$} \\
\hline Ácido gálico & $0.18333 f^{*}$ & $0.44333 \mathrm{f}$ & $0.50333 \mathrm{f}$ & $0.36000 \mathrm{f}$ & 0.012 & 0.030 \\
\hline Catequina & $0.32333 \mathrm{e}$ & $0.22333 \mathrm{~g}$ & $0.18333 \mathrm{~h}$ & $0.20333 \mathrm{~g}$ & 0.019 & 0.062 \\
\hline $\begin{array}{l}\text { Ácido } \\
\text { clorogênico }\end{array}$ & $0.62000 \mathrm{c}$ & $0.64000 \mathrm{e}$ & $0.54000 \mathrm{f}$ & $0.71333 \mathrm{e}$ & 0.031 & 0.101 \\
\hline Ácido cafeico & $0.58333 c$ & $0.76667 d$ & $0.71667 \mathrm{e}$ & $0.34000 \mathrm{f}$ & 0.025 & 0.083 \\
\hline Ácido elágico & $1.13667 \mathrm{~b}$ & $1.05333 \mathrm{~b}$ & $1.06333 \mathrm{~b}$ & $1.33000 \mathrm{~b}$ & 0.008 & 0.027 \\
\hline Epicatequina & $0.22333 \mathrm{f}$ & $0.18000 \mathrm{~g}$ & $0.42667 \mathrm{~g}$ & $0.24000 \mathrm{~g}$ & 0.027 & 0.089 \\
\hline Rutina & $0.12667 \mathrm{~g}$ & $0.52333 \mathrm{f}$ & $0.81667 \mathrm{c}$ & $0.35667 \mathrm{f}$ & 0.023 & 0.075 \\
\hline Quercitrina & $1.25667 \mathrm{a}$ & $1.17000 \mathrm{a}$ & $0.86333 \mathrm{c}$ & $0.98667 d$ & 0.014 & 0.045 \\
\hline Isoquercitrina & $1.23667 \mathrm{a}$ & $0.87667 \mathrm{c}$ & $0.84333 c$ & $1.17333 \mathrm{c}$ & 0.009 & 0.029 \\
\hline Quercetina & $1.12000 \mathrm{~b}$ & $1.24333 \mathrm{a}$ & $1.27333 \mathrm{a}$ & $1.44000 \mathrm{a}$ & 0.016 & 0.053 \\
\hline Canferol & $0.48333 d$ & $0.51000 \mathrm{f}$ & $0.76000 \mathrm{~d}$ & $0.70667 \mathrm{e}$ & 0.022 & 0.073 \\
\hline TOTAL & 7.293 & 7.629 & 7.989 & 7.85 & & \\
\hline
\end{tabular}

$\overline{\mathrm{CL}}$ = Cerro Largo; SE = Segredo; TU = Tupanciretã; SiM = Silveira Martins. Resultados são expressos como média de três determinações. LOD é o limite de deteç̧ão e LOQ é o limite de quantificação. *Médias seguidas por letras diferentes diferem pelo Teste de Scoot-Knott $(p<0,05)$.

Diversos autores já desenvolveram pesquisas sobre a riqueza de compostos provenientes do metabolismo secundário das plantas e sua ação biológica. A abundância de compostos fenólicos foi positivamente correlacionada com ação antimicrobiana sobre Salmonella enteritidis (Medina et al., 2011), assim como atividade antioxidante e antiproliferativa. De acordo com Tomás-Barberán e Espín (2001), esse grupo de metabólitos secundários está relacionado com a prevenção de doenças cardiovasculares e câncer. Além disso, muitos flavonoides, como por exemplo a quercetina que foi o composto majoritário nos extratos aquosos de três dos quatro acessos de $P$. cattleianum analisados aqui, já demostraram a capacidade de induzir a apoptose em células cancerígenas (Chen, Wu, e Lin, 2007).

Além da variabilidade genética entre os acessos, há também influência do clima e principalmente da altitude de cada local onde os genótipos foram coletados, sobre a composição dos extratos aquosos. Os acessos que apresentaram maior quantidade de compostos fenólicos foram os coletados nos municípios de Tupanciretã e Silveira Martins, cidades situadas a mais de 400 metros de altitude. Altitudes mais altas possuem a característica de apresentarem temperaturas menores, principalmente durante o inverno, que é bem rigoroso no estado do Rio Grande do Sul. 
A variação de altitude e temperatura ocasiona diferenças na concentração dos compostos presentes em cada um dos genótipos. Gobbo-Neto e Lopes (2007) confirmaram uma correlação positiva entre a intensidade da radiação solar e a produção de compostos fenólicos, tais como flavonoides, taninos e antocianinas. Os mesmos autores comentam que os flavonoides proporcionam proteção à radiação, assim é possível inferir que estes compostos estão presentes em maior quantidade em plantas de altas altitudes.

Desta forma, conclui-se que os extratos aquosos das folhas de $P$. cattleianum são citotóxicos, pois possuem efeito antiproliferativo em $A$. cepa, sendo proporcional à concentração do extrato aquoso. $O$ acesso $C L$ na menor concentração 15 g. $\mathrm{L}^{-1}$ (CL 15) é considerado genotóxico e os acessos SiM e TU na concentração 15 g.L L $^{-1}$ (SiM 15 e TU 15) considerados antigenotóxicos. A cromatografia líquida de alta eficiência revelou que a quercetina foi o composto fenólico mais abundante em dois acessos (TU e SiM), quercetina e quercitrina no acesso $\mathrm{SE}$, e quercitrina e isoquercitrina foram predominantes no acesso $\mathrm{CL}$. Os compostos secundários de plantas medicinais variam consideravelmente de acordo com vários fatores, provavelmente influenciando o seu valor terapêutico.

\section{Agradecimentos}

Agradecemos à Professora Doutora Margareth Linde Athayde (in memorian) pela valiosa colaboração. Apoio financeiro: Pibic/Cnpq.

\section{Referências}

1. AlAerTS, G.; MATTHIJS, N.; VerBeKE, J.; HEYDEN, Y. Chromatographic fingerprint development for herbal extract: A screening and optimization methodology on monolithic columns. Journal of Chromatography A, 1172, p.1-8, 2007.

2. ANVISA. Agência Nacional de Vigilância Sanitária. Informe Técnico no 45, de 28 de dezembro de 2010.

3. AYRES, M. et al. 2007. BioEstat: aplicações estatísticas nas áreas das ciências biomédicas. Belém: ONG Mamiraua. 364p.

4. BOLIGON, A.A.; KUBIÇA, T.F.; MARIO, D.N.; BRUM, T.F.; PIANA, M.; WEINBLEN, R.; LOVATO, L.; ALVES, S.H.; SANTOS, R.C.V.; ALVES, C.F.S.; ATHAYDE, M.L. Antimicrobial and antiviral activity-guided fractionation from Scutia buxifolia Reissek extracts. Acta Physiologiae Plantarum, 35, p. 2229-2239, 2013.

5. BRIGHENTI, F.L.; LUPPENS, S.B.I.; DELBEM, A.C.B.; DENG, D.M.; HOO-GENKAMP, M.A.; GAETTI-JARDIM, E. Jr.; DEKKER, H.L.; CRIELAARD, W., TEN CATE, J.M. Effect of Psidium cattleianum leaf extract on Streptococcus mutans viability, protein expression and acid production. Caries Research, 42, p. 148-154, 2008.

6. CABRERA, G.L.; RODRIGUEZ, D.M.G. Genotoxicity of soil from farmland irrigated with wastewater using three plant biossays. Mutation Research, 426, p. 211-214, 1999.

7. CHEN, C.N.; WU, C.L.; LIN, J.K. Apoptosis of human melanoma cells induced by the novel compounds propolin A and propolin B from Taiwenese propolis. Cancer Letters, 245, p. 218-231, 2007. 
8. COSTA, T.D.A.; VIEIRA, S.; ANDRADE, S.F.; MAISTRO, E.L. Absence of mutagenicity effects of Psidium cattleyanum Sabine (Myrtaceae) extract on peripheral blood and bone marrow cells of mice. Genetics and Molecular Research, 7, p. 679-686, 2008.

9. DECKER, E.A. Phenolics: prooxidants or antioxidants?. Nutrition Reviews, 55, p. 396-407, 1997.

10. DIAS, M.G.; CANTO-DOROW, T.S.; COELHO, A.P.D.; TEDESCO, S.B. Efeito genotóxico e antiproliferativo de Mikania cordifolia (L. F.) Willd. (Asteraceae) sobre o ciclo celular de Allium cepa L. Revista Brasileira de Plantas Medicinais, 16, p. 202-208, 2014.

11. FACHINETTO, J.M.; BAGATINI, M.D.; DURIGON, J.; SILVA, A.C.F.; TEDESCO, S.B. Efeito anti-proliferativo das infusões de Achyrocline satureioides DC (Asteraceae) sobre o ciclo celular de Allium cepa. Revista Brasileira de Farmacognosia, 17, p. 49-54, 2007.

12. FRESCURA, V.D.; KUHN, A.W.; LAUGHINGHOUSE IV, H.D.; NICOLOSO, F.T.; LOPES, S.J.; TEDESCO, S.B. Evaluation of the allelopathic, genotoxic, and antiproliferative effect of the medicinal species Psychotria brachypoda and Psychotria birotula (Rubiaceae) on the germination and cell division of Eruca sativa (Brassicaceae). Caryologia, 66, p. 138-144, 2013a.

13. FRESCURA, V.D.; KUHN, A.W.; LAUGHINGHOUSE IV, H.D.; PARANHOS, J.T.; TEDESCO, S.B. Post-treatment with plant extracts used in Brazilian folk medicine caused a partial reversal of the antiproliferative effect of glyphosate in the Allium cepa test. Biocell, 37, p. 23-28, 2013b.

14. GOBBO-NETO, L.; LOPES, N.P. Plantas medicinais: fatores de influência no conteúdo de metabólitos secundários. Química Nova, 30, p. 374-381, 2007.

15. GUERRA, M.; SOUZA, M.J. 2002. Como observar cromossomos: um guia de técnicas em citogenética vegetal, animal e humana. Ribeirão Preto: FUNPEC. 131p.

16. KNOLL M.F.; SILVA A.C.F.; CANTO-DOROW T.S.; TEDESCO S.B. Effects of Pterocaulon polystachyum DC. (Asteraceae) on onion (Allium cepa) root-tip cells. Genetics and Molecular Biology, 29, p. 539-542, 2006.

17. KURÁS, M.; NOWAKOWSKA, J.; SLIWINSKA, E.; PILARSKI, R.; ILASZ, R.; TYKARSKA, T.; ZOBEL, A.; GULEWICZ, K. Changes in chromosome structure, mitotic activity and nuclear DNA content from cells of Allium Test induced by bark water extract of Uncaria tomentosa (Willd.) DC. Journal of Ethnopharmacology, 107, p. 211-221, 2006.

18. IM, I.; PARK, K-R.; KIM, S-M.; KIM, C.; PARK, J.H.; NAM, D., JANG, H-J., SHIM, K.S.; MOSADDIK, A.; SETHI, G.; CHO, S.K.; AHN, K.S. The butanol fraction of guava (Psidium cattleianum Sabine) leaf extract suppresses MMP-2 and MMP-9 expression and activity through the suppression of the ERK 1/2 MAPK signalling pathway. Nutrition and Cancer, 64, p. 255-266, 2012.

19. JUN, N.J.; MOSADDIK, A.; MOON, J-Y.; JANG, K-C.; LEE, D-S.; AHN, K.S.; CHO, S.K. Cytotoxic activity of b-caryophyllene oxide isolated from Jeju guava (Psidium cattleianum Sabine) leaf. Records of Natural Products, 5, p. 242-246, 2011.

20. MARTINS, E. R. et al. 2003. Plantas Medicinais. Viçosa: Editora UFV. 220 p.

21. MEDINA, A.L.; HAAS, L.I.R.; CHAVES, F.C.; SALVADOR, M.; ZAMBIAZI, R.C.; da SILVA, W.P.; NORA, L.; ROMBALDI, C.V. Araçá (Psidium cattleianum Sabine) fruit extracts with antioxidant and antimicrobial activities and antiproliferative effect on human cancer cells. Food Chemistry, 128, p. 916-922, 2011. 
22. MENEZES, T.E.C.; DELBEM, A.C.B.; BRIGHENTI, F.L.; OKAMOTO, A.C.; GAETTI-JARDIM, E. $J R$. Protective efficacy of Psidium cattleianum and Myracrodruon urundeuva aqueous extracts against caries development in rats. Pharmaceutical Biology, 48, p. 300-305, 2010.

23. MOON, J.Y.; MOSADDIK, A.; KIM, H.; CHO, M.; KYOON CHOI, H.K.; KIM, Y.S.; CHO, S.K. The chloroform fraction of guava (Psidium cattleianum Sabine) leaf extract inhibits human gastric cell proliferation via induction of apoptosis. Food Chemistry, 125, p. 369375, 2011.

24. PASTORI, T.; FLORES, F.C.; BOLIGON, A.A.; ATHAYDE, M.L.; da SILVA C.B., CANTODOROW, T.S., TEDESCO, S.B. Genotoxic effects of Campomanesia xanthocarpa extracts on Allium cepa vegetal system. Pharmaceutical Biology, 51, p. 1249-1255, 2013.

25. PAVANELO, L.B. Potencial antiproliferativo e determinação de compostos fenólicos de Cordia trichotoma (Vell.) Arráb. ex Steud. 2014. 58 p. Dissertação (Prpgrama de Pósgraduação em Agrobiologia - Mestrado) - Universidade Federal de Santa Maria - UFSM, 2014.

26. PEROZA, L.R.; BUSANELlO, A.; LEAL, C.Q.; ROPKE, J.; BOligON, A.A.; MEINERZ, D.; LIBARDONI, M.; ATHAYDE, M.L.; FACHINETTO, R. Bauhinia forficata prevents vacuous chewing movements induced by haloperidol in rats and has antioxidant potential in vitro. Neurochemical Research, 38, p. 789-796, 2013.

27. RAI, L.K.; PRASAD, P.; SHARMA, E. Conservation threats to some important medicinal plants of the Sikkin Himalaia. Biological Conservation, 93, 1, p. 27-33, 2000.

28. ROQUE, N.F.; VILEGAS, W.; GIANELLA, T.L.; KNUDSEN, F.S.; RONDELLA, G.; TORRES, L.M.B.; FERRO, V.O.; OLIVEIRA, F. Estudo químico de Solidago microglossa, Mikania triangularis, $M$. diversifolia, M. smilacina, M. microlepsis e Wedelia paludosa. Suplemento Acta Amazônica, 18, p. 473-476, 1988.

29. SHENG, Y.; BRYNGELSSON, C.; PERO, R.W. Enhanced DNA repair, immune function and reduced toxicity of C-MED-100, a novel aqueous extract from Uncarla tomentosa. Journal of Ethnopharmacology, 69, p. 115-126, 2000.

30. SILVA, F.A.S. ASSISTAT - Assistência estatística, versão 7.7 beta. Programa computacional. Universidade Federal de Campina Grande Campus de Campina GrandePB - DEAG/CTRN. 2014.-

31. SMOLAREK, F.S.F.; NUNES, P.M.P.; CANSIAN, F.C.; MERCALI, C.A.; CARVALHO, J.L.S.; DIAS, J.F.G.; MIGUEL, O.G. Abordagem fitoquímica e das atividades biológicas da espécie vegetal Solidago microglossa D.C. Visão Acadêmica, v. 10, p. 77-82, 2009.

32. SOUZA, L.F.B.; LAUGHINGHOUSE IV, H.D.; PASTORI, T.; TEDESCO, M.; KUHN, A.W.; CANTO-DOROW, T.S.; TEDESCO, S.B. Genotoxic potential of aqueous extracts of Artemisia verlotorum on the cell cycle of Allium cepa. International Journal of Environmental Studies, 67, p. 871-877, 2010.

33. STURBELLE, R.T.; PINHO, D.S.; RESTANI, R.G.; OLIVEIRA, G.R.; GARCIAS, G.L.; MARTINOROTH, M.G. Avaliação da atividade mutagênica e antimutagênica da Aloe vera em teste de Allium cepa e teste de micronúcleo em linfócitos humanos binucleados. Revista Brasileira de Farmacognosia, 20, p. 409-415, 2010.

34. TEDESCO, S.B.; LAUGHINGHOUSE IV, H.D. Bioindicator of Genotoxicity: The Allium cepa Test. In: SRIVASTAVA, J.K. (Ed.). Environmental Contamination. Rijeka: InTech, 2012. p. 
137-156. Disponível em: <http://www.intechopen.com/books/environmentalcontamination/bioindicator-of-genotoxicity-the-allium-cepa-test>.

35. TEIXEIRA, R.O.; CAMPAROTO, M.L.; MANTOVANI, M.S.; VICENTINI, V.E.P. Assessment of two medicinal plants, Psidium guajava $\mathrm{L}$. and Achillea millefolium L., in vitro and in vivo assays. Genetics and Molecular Biology, 26, p. 551-555, 2003.

36. TOMÁS-BARBERÁN, F.A.; ESPÍN, J.C. Phenolic compounds and related enzymes as determinants of quality in fruits and vegetables. Journal of the Science of Food and Agriculture, London, 81, p. 853-876, 2001.

37. TORRES, L.M.B.; AKISUE, M.K.; ROQUE, N.F. Quercitrina em Solidago microglossa DC, a arnica do Brasil. Revista de Farmácia e Bioquímica, 23, p. 33-40, 1987.

Tabela 1 - Número de células de Allium cepa analisadas em interfase, em divisão, presença de irregularidades e ainda índices genotóxicos (IG) e índices mitóticos (IM) dos controles e tratamentos com extratos aquosos de quatro acessos de Psidium catteianum.

Tabela 2 - Número de células de Allium cepa analisadas em interfase, em divisão, presença de irregularidades e ainda índices genotóxicos (IG) e índices mitóticos (IM) dos controles e dos pós-tratamentos.

Tabela 3 - Compostos fenólicos presentes nos extratos aquosos das folhas de Psidium cattleianum Sabine de quatro acessos distintos, obtidos por cromatografia de líquida de alta eficiência (CLAE).

Figura 1 - Células meristemáticas de raízes de cebola em divisão celular: a) CN (controle negativo) - anáfase normal; b) SE 15 (extrato aquoso 15g. $\mathrm{L}^{-1}$, Segredo) - metáfase normal; c) $\mathrm{CL} 15$ (extrato aquoso 15g. $\mathrm{L}^{-1}$, Cerro Largo) - metáfase com quebra cromossômica; d) TU 15 (extrato aquoso $15 \mathrm{~g} \cdot \mathrm{L}^{-1}$, Tupanciretã) - metáfase irregular; e) CP (controle positivo) - anáfase com ponte e quebra; f) ponte na anáfase no CP. Escala: $10 \mu \mathrm{m}$.

Figura 2 - Perfil representativo da cromatografia líquida de alta eficiência dos extratos aquosos de folhas de Psidium cattleianum Sabine: a) acesso 1 - Cerro Largo (CL); b) acesso 2 - Segredo (SE); c) acesso 3 - Tupanciretã (TU); d) acesso 4 - Silveira Martins (SiM); detecção UV a 327 nm. Ácido gálico (pico 1), catequina (pico 2), ácido clorogênico (pico 3), ácido cafeico (pico 4), ácido elágico (pico 5), epicatequina (pico 6), rutina (pico 7), quercitrina (pico 8), isoquercetrina (pico 9), quercitina (10) e canferol (pico 11). 